\title{
O PODER DO CONHECIMENTO GEOGRÁFICO NO ENFRENTAMENTO DOS DESAFIOS DA FORMAÇÃO PARA A CIDADANIA ATIVA NO BRASIL
}

\author{
Rejane Rodrigues ${ }^{1}$ \\ Pontifícia Universidade Católica do Rio de Janeiro
}

Recibido 14/05/2020 Aceptado 23/05/2020

En este artículo presentamos un proyecto didáctico, organizado en el ámbito de un Programa de formación docente en Brasil, cuyo objetivo principal está relacionado con la formación de jóvenes en edad escolar para la ciudadanía activa. En la elaboración e implementación del proyecto titulado Vota 16, se articulan los preceptos de la educación geográfica y de la educación política con el propósito de revelar el conocimiento geográfico como un conocimiento poderoso con respecto a las posibilidades de transformación de la realidad social desigual y excluyente que perdura en el país.

In this paper we present a didactic project, organized within the scope of a teacher training Program in Brazil, whose main objective is related to the training of young students for active citizenship. During the elaboration and implementation of this project, entitled Vota 16, the precepts of geographic education and political education are articulated, with the purpose of revealing geographic knowledge as a powerful knowledge regarding the possibilities of transforming the unequal and excluding social reality that endures in the country.

DOI

https://doi.org/10.15366/didacticas2020.22.004

PALABRAS CLAVE

Educación geográfica; Conocimiento geográfico poderoso; Ciudadanía activa. 


\section{APRESENTAÇÃO}

Num diálogo nem sempre objetivo com a realidade do espaço escolar e da sociedade em geral, algumas das decisões e ações implementadas a partir políticas públicas e programas de governo acabam por afastar a escola das possibilidades de uma aprendizagem transformadora. Assim, considerando-se o papel central das escolas para a formação de cidadãos em sua relação com as condições institucionais da educação e a realidade escolar no Brasil, analisamos neste artigo uma proposta de atividade referenciada nos preceitos do conhecimento poderoso, da cidadania ativa e da educação política.

O debate aqui proposto se justifica pelos desafios colocados à ciência geográfica, à formação de professores e à geografia escolar, a partir de reformas educacionais adotadas recentemente no país, a exemplo da Base Nacional Comum Curricular. A estes somam-se a distância crescente entre a realidade vivida pelo aluno no Brasil e as condições operacionais das escolas públicas e de muitas escolas da rede privada que, com raras exceções, conservam características da escola do século passado.

Preocupados com o crescente desinteresse do jovem pelo conhecimento e o distanciamento dos currículos escolares das questões mais candentes da realidade social que afetam os estudantes em idade escolar, desenvolvemos, no âmbito do Programa de Bolsas de Iniciação à Docência, um projeto didático inovador. Intitulado Vota 16, o projeto foi desenvolvido por estudantes da licenciatura em Geografia da PUC-Rio, em parceria com professores integrantes do PIBID, e implementado numa escola da rede pública de ensino básico do município do Rio de Janeiro.

Embora vários estudos deem destaque à relação entre o conhecimento geográfico e seu uso para fins de controle da sociedade por diferentes estados e grupos no poder, sua importância para a formação do cidadão não pode ser negada. O poder do conhecimento geográfico é, portanto, neste artigo, o ponto de partida para se pensar possibilidades ampliadas para a educação geográfica, consideradas suas contribuições possíveis para a cidadania ativa.

Neste artigo apresentamos o projeto e seus principais resultados, desejando que estes possam servir para pensarmos sobre os caminhos possíveis para tornar o conhecimento geográfico poderoso.

\section{OS PODERES DO CONHECIMENTO GEOGRÁFICO}

No processo de formação de professores uma questão recorrente diz respeito à importância do conhecimento geográfico. Embora, se considere a Geografia como uma ciência de grande relevância, alguns licenciandos em geografia, futuros professores da escola básica, costumam questionar seus professores sobre os conteúdos ensinados e não ensinados às crianças e jovens em idade escolar. Seria o conhecimento geográfico essencial à formação do cidadão? Os conteúdos comumente trabalhados pela Geografia Escolar são relevantes 
para a vida destas crianças e jovens? Por que muitos dos temas discutidos no âmbito acadêmico não frequentam os currículos escolares?

Estas questões parecem frequentar a formação de professores há muito tempo e não resta dúvida de que sua preocupação se reveste de grande importância. Se retomarmos à própria história de consolidação da Geografia como um campo particular da ciência, veremos que o uso ideológico do conhecimento geográfico escolar, numa perspectiva marcadamente conservadora, pôs à geografia escolar (além de outras disciplinas escolares)

“... a missão de despertar nas crianças e nos jovens o sentido de pertencimento a uma comunidade nacional ligada a condições de espacialidade e territorialidade muito concretas (...) a transmissão de uma determinada interpretação do passado e do presente que facilitou a construção e difusão de uma representação comum do território, da forma como foi ocupado e aproveitado, dos símbolos e crenças que seus habitantes compartilham, com o fim de colaborar para a construção de uma identidade coletiva, uma 'consciência nacional' que contribui para a existência da própria nação”. (Lestegás, 2002:180-181)

Dava-se ênfase ao reconhecimento das características físicas, populacionais, econômicas do país e a assimilação de elementos identitários/unitários do Estado nacional, relegando a segundo plano as diferenças internas, as peculiaridades regionais, o projeto político de grupos hegemônicos. Este contexto foi fundamental para a expansão da geografia como matéria escolar em ritmo mais acelerado do que a própria geografia acadêmica, com grande demanda por professores e, ao mesmo tempo, pela formação de professores. E, foi precisamente esta demanda que levou a sua institucionalização nas universidades.

\begin{abstract}
"Em definitivo, a geografia (...) foi uma matéria própria do ensino primário e secundário antes de obter um reconhecimento universitário, sendo as necessidades derivadas do conhecimento escolar as que impulsionaram o desenvolvimento do saber geográfico científico. Portanto, e até época muito recente, era do ensino, de suas necessidades e programas de onde a geografia universitária recebia praticamente todas as suas demandas profissionais." (Lestegás, 2002:182)
\end{abstract}

Se neste período, que se iniciou em fins do século XX, coube à Geografia Escolar a difusão de um discurso propagandístico, marcadamente ideológico e pretensamente acientífico, a fase que se inicia nos anos 1980 converteu o conhecimento geográfico “... em um assunto desnecessário, supérfluo, decorativo, puramente culturalista e, portanto, perfeitamente prescindível”. (Lestegás, 2002:182) 
Estes lugares ocupados pela geografia escolar, somados a um tratamento didático obsoleto (especialmente face ao avanço das tecnologias de comunicação), estão profundamente relacionados a sua desvalorização, estabelecendo-se a necessidade urgente de refletirmos sobre a construção do conhecimento geográfico no âmbito escolar. Seria, então, o conhecimento geográfico difundido no âmbito da formação escolar perigoso, no sentido de se colocar a serviço de ideologias, e, por isso, dispensável para a formação cidadã em sociedades democráticas? Haveria neste conhecimento geográfico um potencial para a formação de cidadãos críticos, ativos e participativos dos processos socioespaciais com vistas à redução das injustiças sociais?

Uma primeira resposta a estas questões deve remeter ao uso ideológico de outras disciplinas, como a História, indicando que não se trata de uma peculiaridade da Geografia, mas das orientações políticas que orientaram a produção do conhecimento em determinados períodos.

Redimida de sua "culpa”, a Geografia Escolar tem buscado reencontrar seu lugar no campo da construção do conhecimento dando ênfase ao seu potencial formativo. Nos manifestos "This is Geography" (Geographical Association, 2000) e "This is geography... in school and beyond” (Geographical Association, 2003), a Associação Britânica de Professores de Geografia, deu destaque a "oportunidades" que se apresentam a partir da disciplina, como a de realizar investigações durante trabalhos de campo, de compreender fenômenos em suas articulações nas escalas local e global e de formar jovens para o exercício pleno da cidadania, dentre outras.

Tal potencial poderia, de acordo com Lestegás ou Hernández, ser mobilizado com recurso às aprendizagens significativas.

“... é preciso recuperar o valor instrutivo e formativo deste conhecimento mediante abordagens rigorosas e científicas que possibilitem aprendizagens significativas, úteis e funcionais em relação com o desenvolvimento intelectual e cívico de cidadãos críticos e comprometidos com a defesa ativa dos valores democráticos." (Lestegás, 2002:182, apud Hernández, 2002)

Embora reconheçamos a importância destas contribuições, buscamos na teoria do conhecimento poderoso referências que nos ajudem a avançar neste debate, possibilitando o resgate do valor das ideias geográficas, ou melhor, a importância do raciocínio geográfico para alcançar um objetivo maior, qual seja de ancorar a Geografia Escolar na perspectiva das aprendizagens transformadoras.

Neste sentido, uma primeira questão a se pensar sobre a construção do conhecimento geográfico escolar diz respeito à especificidade deste conhecimento. Muitas vezes, associado à ideia de transposição didática, como proposto por Yves Chevallard (1985), o saber escolar é apresentado como uma construção derivada do saber acadêmico, numa posição 
subalterna/dependente a este. Não é nosso objetivo negar a importância da teoria desenvolvida por este autor, já que nela dá-se destaque à relação entre o saber escolar e a ciência referente. Contudo, tomamos como pressuposto a natureza específica do conhecimento escolar construído com referência ao conhecimento científico e a informações de outras fontes (imprensa, anuários etc) e associado a uma cultura escolar particular. O conhecimento escolar, transforma profundamente o saber científico de referência até convertê-lo em um saber específico, uma criação original da escola, com finalidades que lhe são próprias, através do qual se transmite uma determinada representação de mundo, cabendo a cada disciplina escolar fornecer um conteúdo específico (Chervel, 1988).

O conhecimento revelasse em nossa proposta como um conhecimento poderoso e que pode, se relacionado a várias correntes e objetos de análise, prover muitos caminhos para se refletir sobre os problemas do real. Young (2008) defende que as escolas devem trazer de volta o conhecimento, recolocando-o no coração do processo de formação da criança e do jovem. Para o autor, o "conhecimento poderoso" (powerful knowledge) está relacionado a questões atuais e futuras, podendo prover poderosos modos de pensamento sobre elas.

No que se refere ao lugar particular reservado ao conhecimento produzido pela ciência geográfica, consideramos que mudanças no processo ensino-aprendizagem articuladas à reestruturação curricular tanto no âmbito da escola básica quanto no campo da formação de professores pode, se relacionado a várias correntes e objetos de análise, prover muitos caminhos para se refletir sobre os problemas do real. Capacitar os estudantes a "pensar geograficamente" e a "agir politicamente" é importante, especialmente se podemos identificar e justificar como este pensamento é poderoso em ajudá-los a compreender o mundo de diferentes formas, particularmente porque o poder das grandes ideias da Geografia pode transformar o modo como os jovens percebem o mundo (Roberts, 2014).

Especificamente quanto ao conhecimento geográfico, de acordo com Brooks, Brut e Fargher (2017), para que este seja "poderoso" deve-se considerar: a natureza da política e da prática educacional; as condições da Geografia como campo disciplinar; os debates sobre o conhecimento disciplinar.

A relevância destas considerações se assenta na possibilidade de colaborarmos para o repensar do ensino escolar no Brasil, consideradas as possibilidades de consolidação do poder formativo da Geografia e da amplificação do alcance da educação geográfica com fins à promoção de uma urgente e necessária educação política do jovem cidadão em nosso país. Consideramos o jovem em formação em seu papel como agente de produção e transformação da realidade socioespacial, sendo urgente e fundamental a articulação entre a educação geográfica e a educação política. 


\section{EDUCAÇÃO GEOGRÁFICA E EDUCAÇÃO POLÍTICA: DIÁLOGOS POSSÍ- VEIS}

Em nosso tempo, para se falar de política é preciso, como demonstrado por Arendt (2013), começar pelos preconceitos que todos nós, a exceção dos políticos profissionais, temos contra a política. Por isso, defende a autora, a política tem de lidar sempre e em toda parte com esclarecimento e com a dispersão de preconceitos. Propomos, em nossas reflexões, que a escola e, em particular, a educação geográfica tem um importante papel a cumprir neste campo.

Um primeiro e importante desafio diz respeito ao reconhecimento do lugar e papel do cidadão na sociedade. Os cidadãos, de acordo com a teoria constitucional moderna, são os indivíduos, livres e iguais perante a lei, portadores de direitos e deveres estabelecidos pelos mecanismos institucionais do Estado. Contudo, no Brasil e noutros países do mundo, em face da dificuldade de se definir quem são os iguais e quem estabelece as leis, os direitos são vistos como concessões, frente ao Estado, expressando-se a cidadania de modo parcial, desequilibrado e excludente. Deve-se, portanto, como um primeiro movimento, distinguir a cidadania passiva (outorgada pelo Estado) da cidadania ativa, entendida como aquela que institui o cidadão como portador de direitos e deveres, mas também e essencialmente criador de direitos para abrir novos espaços de participação política (Benevides, 1994).

A cidadania ativa define-se pelas possibilidades de representação política e de participação popular direta - a exemplo de mecanismos institucionais como o referendo, o plebiscito e a iniciativa popular introduzidos a partir da Constituição brasileira de 1988 (Benevides, 1994). A cidadania ativa pressupõe a democracia, definida, ainda, pela possibilidade de criação de espaços sociais de luta, de expressão política e de exercício do poder público (Chauí, 1984).

“... entender a participação popular como uma "escola de cidadania" implica rejeitar aquela argumentação contrária que exagera as condições de apatia e despreparo absoluto do eleitorado, assim considerado incapaz, submisso e "ineducável". O que importa, essencialmente, é que se possa garantir ao povo a informação e a consolidação institucional de canais abertos para a participação - com pluralismo e com liberdade.” (Benevides, 1994:3)

Desse modo, concordando que a escola, de um modo ou de outro, institui a cidadania (Arroyo, 2010) e considerados os objetivos de mobilização social, buscamos a construção de propostas didáticas que permitam aos diferentes sujeitos sociais compreender e desenvolver a competência de intervir na sua realidade para sua compreensão e transformação. Buscamos o estabelecimento de nexos entre a educação política, "entendida como educação para cidadania ativa" (Benevides, 1994), e a educação geográfica de modo a contribuir para a ressignificação do conhecimento geográfico escolar e para a promoção de aprendizagens transformadoras. 


\section{CONTRIBUIÇÕES DO PROJETO VOTA 16 PARA FORMAÇÃO DE CIDA- DÃOS ATIVOS}

Num ensaio de aproximação aos preceitos enunciados anteriormente foi organizado, no âmbito das atividades voltadas à formação de professores de Geografia na Pontifícia Universidade Católica do Rio de Janeiro, PUC-Rio, o projeto didático intitulado Vota 16 o qual teve como objetivo principal inserir o aluno no contexto das eleições brasileiras de 2014.

O Vota 16 foi um dos projetos didáticos organizados e implementados no contexto do Programa Institucional de Bolsas de Iniciação à Docência, PIBID, cujo objetivo mais amplo é o de valorizar a profissão docente com efeitos sobre a ampliação do número de estudantes que buscam a carreira de professor da escola básica. O curso de licenciatura em Geografia da PUC-Rio, participa desde 2013 do PIBID, uma ação ligada à Política Nacional de Educação que visa proporcionar aos discentes de licenciatura, professores em formação, uma aproximação prática com o cotidiano das escolas públicas de educação básica e com o contexto em que elas estão inseridas. Tendo como propósito a iniciação do licenciando no ambiente escolar, as Instituições de Ensino Superior devem organizar propostas que estimulem a observação e a reflexão sobre a prática profissional no cotidiano das escolas públicas de educação básica.

$\mathrm{Na}$ ocasião da implementação do projeto apresentado neste artigo, participavam do PIBID Geografia PUC-Rio, 30 licenciandos e 2 professores do Departamento de Geografia da PUC-Rio, além de 4 professores de geografia de uma escola da rede básica de ensino do município do Rio de Janeiro. Alunos de diferentes níveis de ensino, do $6^{\circ}$ ao $9^{\circ}$ ano do ensino fundamental, com idades entre 11 e 16 anos de idade, participaram das atividades.

Em acordo com os propósitos estabelecidos quanto à aproximação da educação geográfica aos preceitos do conhecimento poderoso e da cidadania ativa, os participantes do PIBID Geografia da PUC-Rio têm refletido sobre os desafios da geografia escolar, buscando alternativas didático-pedagógicas, ancoradas nas mais importantes teorias educacionais, para a implementação de uma aprendizagem transformadora em escolas da rede pública de ensino do Brasil.

Face ao acirrado contexto político-eleitoral relacionado às eleições presidenciais de 2014, quando foram escolhidos o Presidente da República, os Governadores dos estados, os Senadores e os Deputados federais e estaduais, os licenciandos participantes do PIBID Geografia da PUC-Rio observaram o crescente interesse dos alunos de uma escola da rede municipal de educação, interesse que se mesclava com o desconhecimento e descrédito quanto à importância da temática da representação política para a transformação social no país. Deve-se destacar que tal temática é muito raramente tratada como conteúdo disciplinar nas escolas brasileiras, talvez uma herança da ditadura civil militar instaurada no Brasil entre os anos 1960 e 1980 e da ideia ainda bastante arraigada na sociedade de que "política e religião não se discute". 
Buscando pensar as possibilidades e alternativas para se (re)colocar o tema da política, da representação política e da participação cidadã no currículo escolar, foi organizado o projeto denominado Vota 16. O nome tem relação com a idade dos jovens estudantes da escola parceira do PIBID e com a legislação brasileira que estabelece o voto obrigatório a partir dos 18 anos e facultativo a partir dos 16 anos. De acordo com a legislação eleitoral, alguns alunos da escola já eram, e outros estavam em vias de se tornar, eleitores aptos a participar do pleito. Apesar desta condição legalmente instituída, o direito ao voto e a possibilidade de participação por outros meios não parecia mobilizar aqueles jovens. Ao contrário, revelava uma realidade de descrédito e recusa à participação política e as possibilidades de transformação social pela via da cidadania ativa. Neste sentido, estabeleceuse como objetivo do projeto a compreensão da importância da política, da representação política e da participação cidadã para a transformação social com fins à ampliação da justiça social no Brasil.

O projeto foi organizado, buscando-se articular: os pressupostos teóricos anteriormente apresentados; as condições operacionais da escola parceira; a idade e o nível cognitivo dos alunos; o planejamento escolar da série. Para tal dividiu-se a atividade da seguinte forma:

Etapa 1: Realização de eleições simuladas tendo como referência apenas o conhecimento pretérito dos alunos da escola parceira. Foram disponibilizadas cédulas eleitorais com os nomes e partidos políticos dos nove candidatos que concorreram ao pleito em 2014 . O resultado, contabilizado pelos participantes do PIBID, das eleições simuladas não foi divulgado para os alunos da escola.

Etapa 2: Os alunos foram convidados a apresentar suas impressões sobre as competências das diferentes esferas do poder público e dos mecanismos de representação política no Brasil. O resultado da simulação e estas informações foram reunidas e analisadas como material de base para a organização das etapas seguintes do projeto Vota 16.

Etapa 3: Leitura e análise, pelos licenciandos participantes do PIBID, de artigos acadêmicos, documentos e dados oficiais sobre os níveis de poder (legislativo, executivo e judiciário), suas escalas de representação (federal, estadual e municipal), as especificidades da representação política e os mecanismos de participação política no Brasil. Tomando como base o apreendido nesta etapa da atividade, os licenciandos produziram um material didático textual destinado a tornar compreensível a realidade político-institucional e políticopartidária brasileira, tema de grande complexidade, o qual foi adaptado conforme a série escolar e a idade dos alunos das turmas participantes.

Etapa 4: Considerando a visão prévia dos alunos sobre a política e a representação política no Brasil, foram propostas atividades por série.

- turmas do $6^{\circ}$ ano do ensino fundamental (alunos com idade média de 11 anos) levantamento e mapeamento do domicílio eleitoral dos candidatos à Assembleia Legislativa do Rio de Janeiro (deputados estaduais). O objetivo principal era de 
observar se havia sub-representação de municípios periféricos no contexto do estado do Rio de Janeiro. A partir do mapeamento, os alunos puderam constatar que há grande concentração espacial da representação política no estado com a maioria dos candidatos representando a Região Metropolitana do Rio de Janeiro, RMRJ, reforçando a oposição capital-interior com efeitos sobre a atração de maiores volumes de recursos para a RMRJ. O mapa produzido foi exposto na escola e os alunos convidados a explicá-lo para os colegas.

○ turmas do $7^{\circ}$ ano do ensino fundamental (alunos com idade média de 12/13 anos) - levantamento de informações sobre as competências de cada representante político no Brasil (Vereadores, Deputados estaduais e federais, Senadores e Presidente) e posterior análise de propagandas políticas de candidatos selecionados. Os alunos foram organizados em cinco grupos e cada grupo convidado a produzir folhetos com as competências um grupo de representantes. Os folhetos foram distribuídos entre os alunos das outras turmas da escola. Nesta atividade, os alunos puderam observar que nem sempre há coerência entre as propostas apresentadas pelo candidato e sua futura esfera de atuação política. Situação bastante comum no Brasil durante as campanhas eleitorais, sobretudo, quando se trata dos níveis de representação mais próximos do eleitorado.

○ turmas do $8^{\circ}$ ano do ensino fundamental (alunos com idade média de 13/14 anos) - Levantamento e análise da plataforma eleitoral de candidatos à presidência do Brasil, seguido de debate para comparação das propostas no âmbito dos objetivos mais gerais dos partidos de direita e de esquerda e dos desafios para redução da injustiça social no país. Cabe destacar que os licenciandos produziram um material complementar destinado a esclarecer as principais diferenças entre tendências políticas consideradas de direita e de esquerda, bem como os preceitos fundamentais da justiça social nas sociedades contemporâneas. A atividade foi seguida pela produção, pelos alunos organizados em grupos, de plataformas eleitorais organizadas por temas (educação ou saúde ou transporte etc) as quais deveriam, obrigatoriamente, considerar suas condições de vida e as demandas mais urgentes dos grupos sociais mais vulneráveis do país. As plataformas eleitorais de cada grupo foram expostas na escola, devendo os alunos apresentar suas ideias aos colegas da escola.

- turmas do $9^{\circ}$ ano (alunos com idade média de 14/16 anos) - Análise de propagandas eleitorais de candidatos à presidência veiculados na TV¹ , observando-se as estratégias eleitorais dos candidatos e de seus partidos ou coligações. A partir do observado, os alunos organizados em grupos deveriam, com o apoio dos materiais

\footnotetext{
${ }^{1}$ O horário eleitoral gratuito corresponde a um tempo reservado por lei, na programação de emissoras de televisão e de rádio, para propaganda eleitoral (apresentação de programas de governo) de candidatos a vagas eletivas no poder executivo e legislativo brasileiro.
} 
produzidos pelas outras turmas e, em especial, das plataformas eleitorais produzidas pelos colegas do $8^{\circ}$ ano, criar um candidato hipotético à presidência e produzir um vídeo de propaganda eleitoral no qual os alunos deveriam dar destaque à adoção de medidas para redução das desigualdades socioespaciais no país. Os vídeos foram expostos na escola durante uma semana.

Etapa 5: Realização da segunda rodada de eleições simuladas. Do mesmo modo que na primeira rodada, foram disponibilizadas cédulas eleitorais com os nomes e partidos políticos dos nove candidatos que concorreram ao pleito em 2014. O resultado das eleições foi analisado comparativamente ao resultado daquela realizada na primeira etapa, com o intuito de observar o impacto do trabalho realizado na percepção dos alunos sobre o processo eleitoral no Brasil. Embora o resultado desta simulação ainda tenha expressado a grande influência da campanha eleitoral em curso no país, observou-se importante mudança quanto às escolhas dos alunos que participaram do projeto.

Neste sentido, tomando-se como referência não apenas a simulação do pleito eleitoral, mas também e, principalmente, as observações registradas pelos licenciandos e professores participantes do PIBID durante a implementação do projeto Vota 16, damos destaque a algumas importantes considerações:

○ dificuldade de compreensão e, até mesmo, desconhecimento quanto à estrutura político-administrativa do país e das estruturas de poder a ela relacionadas, conteúdo superficialmente ou nunca abordado pelas disciplinas escolares e/ou reservado ao campo da memorização;

- necessária e atenta observação das competências legislativas e da sub-representação política de localidades de menor expressão político-econômica no país em relação aquelas de maior destaque;

- desconhecimento das possibilidades instituídas de participação política direta e indireta e dificuldade de compreensão destes como mecanismos de transformação das condições sociais;

○ desânimo dos alunos com relação à efetividade da representação política no que tange à transformação das suas condições objetivas de vida;

○ visão pasteurizada quanto à atuação dos representantes políticos eleitos, associados comumente a um imaginário de oportunistas e corruptos, a exemplo da frase proferida por um aluno "político é tudo ladrão"; 
Apesar de algumas dificuldades enfrentadas durante a realização do projeto, o grupo de participantes do PIBID Geografia da PUC-Rio avaliou positivamente a experiência, sobretudo pelo interesse pelo tema demonstrado pelos alunos da escola durante outras aulas ocorridas após a finalização do projeto.

O grupo deu destaque à maior "animação" observada no cotidiano da escola e o envolvimento voluntário de grande parte dos alunos durante a realização do projeto Vota 16, indicando as possibilidades para ampliação do interesse por temas e metodologias de maior significância para a formação destes jovens. Concluiu pela importância em se observar na formulação de currículos escolares a dificuldade de compreensão e, até mesmo, o desconhecimento quanto à estrutura político-administrativa do país e de poder a ela relacionadas, conteúdo superficialmente ou nunca abordado pelas disciplinas escolares ou, ainda, tratado na perspectiva da memorização. E, indicou a necessidade da geografia escolar em dar ênfase no trabalho com as escalas de análise, para além das escalas cartográficas, possibilitando a melhor compreensão de temas como o das competências legislativas.

Do ponto de vista da formação de professores, acreditamos ter colaborado para o reconhecimento pelos licenciandos, futuros professores, da importância do conhecimento geográfico para a cidadania ativa e dos efeitos possíveis para a formação de jovens envolvidos com projetos de transformação da realidade social e excludente que predomina no Brasil.

\section{CONSIDERAÇÕES FINAIS}

Considerados nossos propósitos quanto à busca por alternativas didático-pedagógicas que confirmem o importante papel da geografia escolar para a formação cidadã, apresentamos neste artigo um projeto didático apoiado na articulação entre a educação geográfica e a educação política.

Embora este projeto tenha sido implementado durante o pleito eleitoral de 2014, passados seis anos, o conturbado momento político do Brasil atual, marcado pela adoção de medidas que resultam na retração de direitos civis e na constante ameaça à democracia, nos recoloca face a questões tratadas naquela ocasião e, principalmente, indica a importância de projetos como o Vota 16 e do conhecimento geográfico concebido como um conhecimento poderoso no sentido da formação de cidadãos críticos, ativos e participativos.

Este projeto e os resultados alcançados a partir da sua implementação têm servindo como referência para a estruturação de outras propostas didáticas relacionadas aos propósitos mais gerais de articulação dos objetivos da educação geográfica aos princípios da educação política para a cidadania ativa e, principalmente para o repensar do currículo escolar considerados os desafios de superação das desigualdades socioespaciais que marcam a realidade brasileira. 


\section{REFERENCIAS}

ARENDT, H. (2002) O que é Política? Rio de Janeiro: Bertrand Brasil. $3^{\text {a }}$.ed.

ARROYO, M., BUFFA, E. e NOSELLA, P. (2010) Educar para a Cidadania, quem educa o cidadão? São Paulo: Martins Fontes. $14^{\mathrm{a}}$.ed.

BENEVIDES. M. V. (1994) Cidadania e democracia. São Paulo:Lua Nova.

BROOKS, C., BRUTT, G. e FARGHER, M. (edit) (2017) The Power of Geographical Thinking. Springer/IGU: London.

CHAUÍ, M. (1984) Cultura e democracia. São Paulo, Editora Moderna.

CHERVEL, A. (1988). L'histoire des disciplines scolaires: réflexions sur un domaine du recherche. Histoire de l'Éducation, nº38, pp.59-119.

CHEVALLARD, Y. (1985): La transposition didactique. Du savoir savant au savoir enseigné. Grenoble, La Pensée Sauvage. ed. 1991.

CHERVEL, A. (1988) L'histoire des disciplines scolaires. Réflexions sur um domanine de recherche. Histoire de l'Éducation, nº 38, pp. 59-119.

Geographical Association (2000). This is Geography, Sheffield. [Enlace].

Geographical Association (2003). This is Geography in school and beyound, Sheffield. [Enlace].

LESTEGÁS, F. R. (2002) Concebir la Geografía Escolar desde una Perspectiva: una disciplina al servicio de la cultura escolar. Boletin de La AGE, n³3.

ROBERTS, M. (2014) Powerful Knowledge and geographical education. The Curriculum Journal, 25(2): 187-209.

YOUNG, M. (2008) From constructivism to realism in the sociology of education. Review of Research in Education, 32:1-28. 